\title{
High Dose Oral Steroids Commonly Used to Treat Relapses in Canadian MS Clinics
}

\author{
Morrow SA, Metz LM, Kremenchutzky M
}

\begin{abstract}
Background: Glucocorticoid treatment improves the speed of functional recovery of acute multiple sclerosis (MS) relapses but has not been shown to provide any long-term functional benefit. There is currently no convincing evidence that the clinical benefit is influenced by the route of administration or the dosage of glucocorticoid, or the particular glucocorticoid prescribed. Recent studies support similarities in the bioequivalence and in the clinical effect of high dose oral corticosteroids for MS relapses. Objective: This survey aimed to determine the relapse treatment preferences of clinicians in Canadian MS clinics. Methods: Members of the Canadian Network of MS Clinics are linked by an email server. A one page survey was distributed to the group to determine and report use of corticosteroids to manage MS relapses amongst Canadian MS specialists. Results: Fifty-one clinicians from 17 MS clinics were surveyed. $32(63 \%)$ surveys were returned representing 16 clinics. Five doses are most commonly prescribed, usually without a taper. Three or four doses and the use of a corticosteroid taper, however, are not uncommon. Gastric cytoprotection and sedatives are often prescribed for use as needed. Conclusion: This survey illustrates that when Canadian clinicians with expertise in managing MS treat MS relapses they choose high dose corticosteroids, either oral or IV. The results therefore represent Canadian practice as these clinicians provide direct patient care and influence care by community neurologists. Until evidence clearly identifies a superior practice all options should be available to clinicians and their patients.
\end{abstract}

RÉSUMÉ: Stéroïdes à hautes doses utilisés fréquemment pour traiter les récidives dans les cliniques de SP au Canada. Contexte : Le traitement par les glucocorticoïdes accélère la récupération fonctionnelle lors d'une récidive aiguë de sclérose en plaques (SP). Cependant il n'a jamais été démontré que ce traitement offre un bénéfice fonctionnel à long terme. Il n'existe pas actuellement de données convaincantes que le bénéfice clinique soit influencé par la voie d'administration ou le dosage des glucocorticoïdes ou le glucocorticoïde spécifique prescrit. Des études récentes appuient la notion d'une bioéquivalence et d'une similitude de l'effet clinique de hautes doses de corticostéroïdes administrés par voie orale dans la récidive de la SP. Objectif : Le but de cette enquête était de déterminer les préférences des cliniciens oeuvrant dans les cliniques de SP au Canada quant au traitement des récidives. Méthodes : Les membres du Réseau canadien de cliniques de SP sont reliés par un serveur de courrier électronique. Un questionnaire d'une page a été distribué aux membres du réseau afin d'étudier et de rapporter l'utilisation des corticostéroïdes dans le traitement des récidives par les spécialistes canadiens de la SP. Résultats : Cinquante et un cliniciens travaillant dans 17 cliniques de SP ont reçu le questionnaire. Trente-deux (63\%) des questionnaires ont été retournés par des cliniciens travaillant dans 16 cliniques. Cinq doses sont plus souvent prescrites, habituellement sans réduction progressive de la dose. Il n'est cependant pas rare que trois ou quatre doses avec réduction progressive soient prescrites. Une cytoprotection gastrique et des sédatifs sont souvent prescrits, à utiliser au besoin. Conclusion : Cette étude indique que, quand les cliniciens canadiens experts dans le traitement de la SP traitent des récidives de la maladie, ils prescrivent de hautes doses de corticostéroïdes par voie orale ou intraveineuse. Ces résultats représentent donc la pratique canadienne étant donné que ces cliniciens fournissent des soins directs aux patients et qu'ils influencent la pratique des autres neurologues. Toutes les options devraient être disponibles aux cliniciens et à leurs patients tant que la supériorité de l'une ou l'autre n'a pas été établie.

Can. J. Neurol. Sci. 2009; 36: 213-215

A multiple sclerosis (MS) relapse is generally defined as an episode of new neurological dysfunction, or subacute worsening of previous symptoms, that lasts at least 24 hours and is not due to another etiology. Glucocorticoid treatment improves the speed of functional recovery of acute MS relapses but has not been shown to provide any long-term functional benefit. There is currently no convincing evidence that the clinical benefit is influenced by the route of glucocorticoid administration, the particular glucocorticoid prescribed, or the dosage of glucocorticoid $^{1,2}$. Traditionally, IV administration of corticosteroid preparations has been used, but many patients prefer oral therapy, which is less expensive and more convenient ${ }^{3}$. Recent studies support similarities in the bioequivalence and in the clinical effect of high dose oral corticosteroids for MS

From the Department of Clinical Neurosciences (SAM, MK), University of Western Ontario, London, Ontario; Department of Clinical Neurosciences and Hotchkiss Brain Institute (LMM), University of Calgary, Calgary, Alberta, Canada.

Received September 5, 2008. Final Revisions Submitted November 6, 2008. Correspondence to: Marcelo Kremenchutzky, University Hospital, London Health Sciences Centre, 339 Windermere Road, London, Ontario, N6A 5A5, Canada. 
relapses ${ }^{4.5}$. Furthermore, studies support the gastric safety of high dose oral steroids ${ }^{6}$. This survey aimed to determine the relapse treatment preferences of clinicians in Canadian MS clinics.

\section{Methods}

Established in 2001 as a unique collaboration amongst Canadian MS healthcare providers, the Canadian Network of Multiple Sclerosis Clinics (CNMSC) is a consortium of Canadian MS Clinics for patients, clinic staff, physicians, and researchers. The Network currently includes more than 17 specialized centres and has over 50 investigators at 15 universities across the country. Members of the CNMSC are linked by an email server. A one page survey was distributed to the group to determine and report use of corticosteroids to manage MS relapses amongst Canadian MS specialists. Neurologists, physiatrists, and nurse practitioners who independently assess and treat relapses in MS clinics were asked to complete the survey. It was not anonymous to facilitate discussion but initial responses were not changed.

\section{RESULTS}

Fifty-one clinicians from 17 MS clinics were surveyed. Thirty-two $(63 \%)$ surveys were returned representing 16 clinics. All clinicians (29 neurologists, 1 physiatrist, and 2 MS-specialist nurse practitioners) reported that they treat some relapses with corticosteroids. This survey did not explore the clinicians' opinions about indications for treatment. While most clinicians prescribe different corticosteroids and different doses in different situations $47 \%$ reported that they usually prescribe intravenous methylprednisolone (IVMP) and 44\% usually prescribe oral prednisone. Oral methylprednisolone was occasionally also

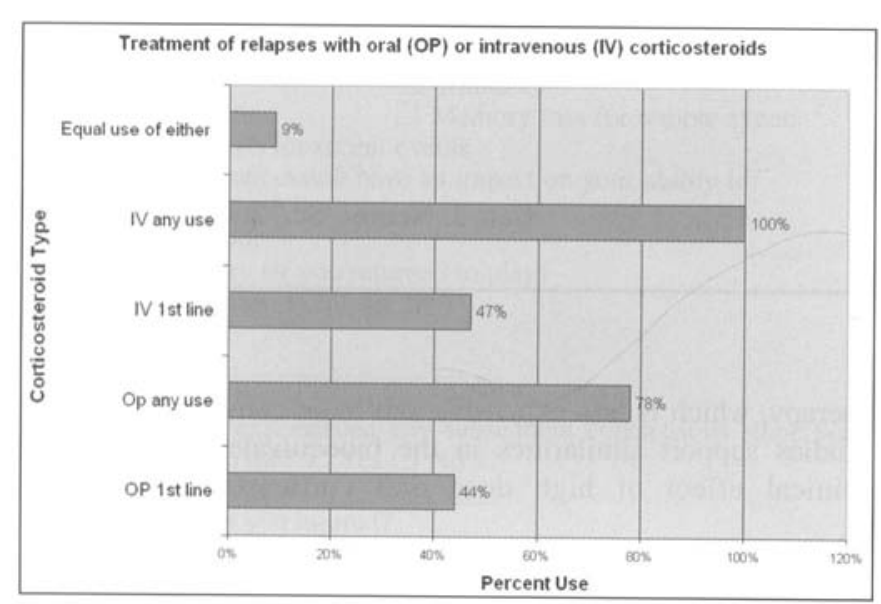

Figure 1: Use of oral (OP) vs. intravenous (IV) corticosteroids for relapses. Similar proportions of $M S$ specialists choose $O P$ and $I V$ corticosteroids as the first line therapy for MS relapses. In contrast, all $M S$ specialists use $I V$ as a preferred treatment at some time in their practice, while a much smaller proportion use oral corticosteroids at any time. prescribed. Furthermore, while $78 \%$ of clinicians reported that they sometimes prescribe oral steroids, all reported that they occasionally prescribe IVMP (Figure 1). Dysphagia, very severe symptoms, and previous intolerance or poor response to oral steroids were common reasons that clinicians who usually prescribe oral steroids, choose to prescribe IVMP. Otherwise, participants did not identify any specific factors (i.e. demographics or EDSS status) to explain or justify their choice. Clinicians did not report low dose oral steroids as a treatment option. Generally $1000-1250 \mathrm{mg}$ of prednisone per dose was prescribed but in some circumstances doses as low as $500 \mathrm{mg}$ of prednisone were prescribed. The number of doses prescribed ranged from 3-6 but $60 \%$ of clinicians usually prescribe 5 doses and $12 \%$ vary the number of doses that they prescribe depending on the circumstances (Figure 2).

A corticosteroid taper was variably prescribed. Most clinicians $(56 \%)$ never or rarely (up to $10 \%$ of relapses) prescribe a taper and $12.5 \%$ prescribe a taper for at least $75 \%$ of relapses. The remainder estimated that they prescribe a taper for between 15 and $70 \%$ of relapses.

Clinicians were also asked about use of co-medication such as gastric cytoprotection and sedatives for insomnia. Gastric cytoprotection including $\mathrm{H} 2$ blockers, proton pump inhibitors or over the counter antacids were prescribed or recommended by $47 \%$ of clinicians but in most cases $(73 \%)$ use was only recommended on an as needed basis. Sedatives were prescribed by $56 \%$ of clinicians but most of these clinicians $(78.5 \%)$ prescribe them only as needed.

\section{DisCUSSION}

The use of corticosteroids for treatment of acute MS relapses remains the standard practice, and treatment effectiveness

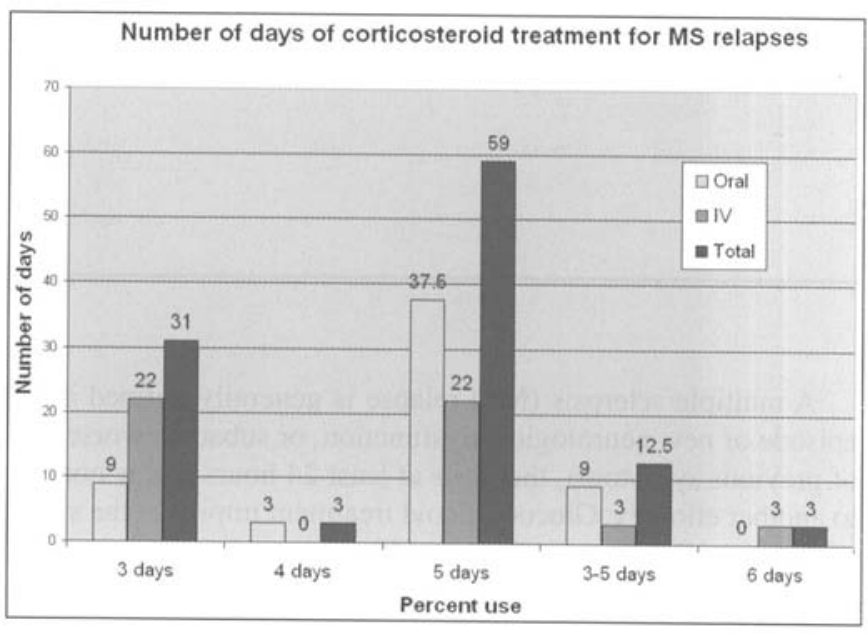

Figure 2: Number of pulses of corticosteroids. The majority of MS specialists use a 3 or 5 day regimen of corticosteroids. However, the choice of pulse number varies with the choice of oral or intravenous (IV) corticosteroids. 
translates into decreased severity and length of exacerbations, their most valuable benefits? ${ }^{7}$ However, there are several other important endpoints that are not often assessed, including the impact on physical handicap, quality of life and healthcare services utilization.

This survey illustrates that when Canadian clinicians with expertise in managing MS treat MS relapses they choose high dose corticosteroids, either oral or IV, with no clear preference for one or the other.

Five doses are most commonly prescribed, usually without a taper. Three or four doses and the use of a corticosteroid taper, however, are not uncommon. Gastric cytoprotection and sedatives are often prescribed for use as needed. This pattern of use fits within the parameters of published evidence and reflects the lack of proof of superiority of either regimen. While the size of the population sampled is small, 63\% of the practicing clinicians in Canadian MS Clinics are represented. The results therefore represent Canadian practice as these clinicians provide direct patient care and influence care by community neurologists and general practitioners.

Although we believe this simple study is very informative, many questions could be further explored. It would certainly be very interesting to know what drives each doctor/nurse/clinic to choose oral vs IV therapy, whether there is any geographical distribution (i.e. inter provincial differences in healthcare delivery or community support, etc) or any patient-specific factor (i.e. age or disability status, etc) that can explain or justify the present study findings. While many of these issues deserve more attention, we have chosen just to focus on treatment of relapses by oral vs IV administration of steroids for the purpose of the present study. More research is certainly needed, but until evidence clearly identifies a superior practice all options should be available to clinicians and their patients.

\section{ACKNOWLEDGEMENTS}

Dr. Sarah Morrow is supported by the 2007-2008 Canadian Network of MS Clinics Don Paty Fellowship.

\section{REFERENCES}

1. Goodin DS, Frohman EM, Garmany GP Jr, Halper J, Liksosky WH, Lublin FD, et al. Disease modifying therapies in multiple sclerosis: Subcommittee of the American Academy of Neurology and the MS Council for Clinical Practice Guidelines. Neurology. 2002; 58(2):169-78.

2. Sellebjerg F, Barnes D, Filippini G, Midgard R, Montalban X, Rieckmann $P$, et al. EFNS guideline on treatment of multiple sclerosis relapses: report of an EFNS task force on treatment of multiple sclerosis relapses. Eur J Neurol. 2005; 12:929-36.

3. Metz LM, Harris CJ, Moore A. MS patients' choice of oral rather than IV steroid therapy results in savings to the health care system. Int J MS Care [serial online] 2000;2(2). Available from http://mscare.com. Accessed online July 2008.

4. Morrow SA, Stoian CA, Dmitrovic J, Chan SC, Metz LM. The bioavailability of IV methylprednisolone and oral prednisone in multiple sclerosis. Neurology. 2004; 63:1079-80.

5. Martinelli V, Pulizzi A, Annovazzi P, Rocca MA, Bucello S, Esposito $\mathrm{F}$, et al. A single blind, randomized MRI study comparing high doses oral and intravenous methylprednisolone in treating MS relapses. [abstract] ECTRIMS Meeting. Oct 14, 2007.

6. Metz LM, Sabuda D, Hilsden RJ, Enns R, Meddings JB. Gastric tolerance of high dose pulse oral prednisone in multiple sclerosis. Neurology. 1999; 53:2093-6.

7. Miller DM, Weinstock-Guttman B, Beathoux F, Lee JC, Beck G, Block V, et al. A meta-analysis of methylprednisolone in recovery from multiple sclerosis exacerbations. Multiple Sclerosis. 2000; 6:267-73. 